\title{
Les Chemins de la Queste, textes réunis par Denis Hüe et Silvère Menegaldo
}

\section{Richard Trachsler}

\section{Q OpenEdition}

10 Journals

\section{Édition électronique}

URL : http://journals.openedition.org/studifrancesi/9754

DOI : 10.4000/studifrancesi.9754

ISSN : 2421-5856

Éditeur

Rosenberg \& Sellier

\section{Édition imprimée}

Date de publication : 1 octobre 2007

Pagination : 414-415

ISSN : 0039-2944

\section{Référence électronique}

Richard Trachsler, "Les Chemins de la Queste, textes réunis par Denis Hüe et Silvère Menegaldo », Studi Francesi [En ligne], 152 (LI | II) | 2007, mis en ligne le 30 novembre 2015, consulté le 09 janvier 2021. URL : http://journals.openedition.org/studifrancesi/9754; DOI : https://doi.org/10.4000/studifrancesi. 9754

Ce document a été généré automatiquement le 9 janvier 2021.

\section{(c)}

Studi Francesi è distribuita con Licenza Creative Commons Attribuzione - Non commerciale - Non opere derivate 4.0 Internazionale. 


\title{
Les Chemins de la Queste, textes réunis par Denis Hüe et Silvère Menegaldo
}

\author{
Richard Trachsler
}

\section{RÉFÉRENCE}

Les Chemins de la Queste, textes réunis par DENIS HÜE et SILVÈRE MENEGALDO, Orléans, Paradigme («Medievalia», 52), 2004, pp. 306.

1 Suivant une coutume assez bien établie depuis quelques années, les éditions Paradigme proposent, sous l'égide de Denis Hüe, un choix d'articles concernant l'œuvre médiévale au programme de l'agrégation de Lettres. En 2004-2005, c'était au tour de la Queste del Saint Graal, et Denis Hüe a bénéficié de Laide de Silvère Menegaldo pour réunir dans ce volume dix-sept articles «classiques», dont quelques-uns traduits en français pour la première fois, ainsi que deux «inédits». Le tout est précédé d'une introduction générale due à Silvère MENEGALDO (pp. 5-8) et suivi d'une bibliographic, assez complète sur la Queste elle-même, et un peu moins, conformément au but du volume, pour ce qui est des rapports avec les autres parties du Lancelot-Graal (pp. 297-303). On y trouvera donc les dix-sept études suivantes: Emmanuèle BAUMGARTNER, «Les aventures du Graal», pp. 9-15; repris de Mélanges de langue et littérature françaises du Moyen Âge et de la Renaissance offerts à Charles Foulon, Rennes, Université de Haute Bretagne, t. I, 1980, pp. 23-28. Daniel PoIRIon, «Semblance du Graal dans la Queste», pp. 17-29; repris de Mélanges de linguistique, de littérature et de philologie médiévales offerts à J.R. Smeets, Leyde, [s. n.], 1982, pp. 227-241, réimpression dans son recueil Écriture poétique et composition romanesque, Orléans, Paradigme, 1994, pp. 201-215. - Nancy Freeman REGALADO, «La chevalerie celestiele. Métamorphoses spirituelles du roman profane dans La Queste del Saint Graal», pp. 31-51; repris de «La chevalerie celestiele. Spiritual Transformations of Secular Romance in La Queste del Saint Graal», in Romance. Generic transformation from Chrétien de 
Troyes to Cervantes, ed. Kevin BROWNLEE and Marina SCORDILIS BROWNLEE, Hanovre / Londres, University Press of New England, 1985, pp. 91-113, traduit de l'anglais par Denis HÜE - Jean-Charles PAYEN, «Le sens du péché dans la littérature cistercienne en langue d'oïl», pp. 53-65; repris de Citeaux, commentarii cistercienses, 13 (1962), pp. 281295. - Jean-Charles PAYEN, «Le motif du repentir dans le Lancelot-Graal», pp. 67-87; extrait de Le motif du repentir dans la littérature française médiévale, Genève, Droz, 1967, pp. 434-454. - Karen PRATT, «Les cister- ciens et la Queste del Saint Graal», pp. 89-112; repris de "The Cistercians and the Queste del Saint Graal», Reading Medieval Studies, 21 (1995), pp. 69-96, traduit de l'anglais par Denis HÜE - Pierre COUPIREAU, «La semblance et les limites de l'homme dans La Queste del Saint Graal», pp. 113-123; repris de Entre l'ange et la bête, l'homme et ses limites au Moyen Âge, éd. Marie-Étiennette BÉLY, Jean-René VALETTE et Jean-Claude VAllecalle, Lyon, Presses Universitaires de Lyon, 2003, pp. 83-95. Renata Anna BARTOLI, «Galaad Figura militis christiani (Senefiances implicites dans La Queste del Saint Graal)», pp. 125-146; repris de «Galaad Figura militis christiani. Senefiance nella Queste del Saint Graal», Museum patavinum, 4 (1986), pp. 341-361, traduit de l'italien par Brigitte HÜE-GIRAUD - Micheline de COMBARIEU DU GRÈS, «Les quêteurs de merveilles. Étude sur La Queste del Saint Graal», pp. 147-162; repris de Revue des Langues Romanes, 100 (1996), pp. 63-90, et réimprimé dans son recueil D’aventures en Aventure. 'Semblances' et 'senefiances' dans le "Lancelot"en prose, Aix-en-Provence, Publications du CUERMA (Senefiance 44), 2000, pp. 431-452. - Micheline de COMBARIEU DU GRÈS, «Du temps perdu au temps retrouvé. Étude sur le temps et les structures romanesques de La Queste del Saint Graal», pp. 163-202; repris de Le temps, sa mesure et sa perception au Moyen Âge, éd. Bernard RIBÉMONT, Caen, Paradigme, 1992, pp. 73-112. - Pierre JONIN, «Les ermites de la quête du Graal», pp. 203-223; repris de Annales de la Faculté des Lettres et Sciences humaines d'Aix, 44 (1968), pp. 326-335. - Jennifer E. LOOPER, «Genre, généalogie: l'histoire des trois fuseaux dans La Queste del Saint Graal», pp. 225-237; repris de «Gender, Genealogy and the Story of the Three Spindles in the Queste del Saint Graal», Arthuriana, 8/1 (1998), pp. 49-66, traduit de l'anglais par Denis HÜE - Ben RAMM, «Por coi la pucele pleure: l'énigme féminine de La Queste del Saint Graal», pp. 239-247; repris de «Por coi la pucele pleure: the feminine enigma of the Grail Quest», Neophilologus, 87/4 (2003), pp. 517-527, traduit de l'anglais par Nicolas COSTIL - Gérard MOIGNET, «La grammaire des songes dans La Queste del Saint Graal», pp. 249-257; repris de Langue française, 40 (1978), pp. 113-119 (l'indication de la publication originale a été omise, mais se retrouve grâce à la bibliographie finale) - Christiane MARCHELLO-NIZIA, «Les voix dans La Queste del Saint Graal: grammaire du surnaturel, ou grammaire de l'intériorité?», pp. 259-266; repris de Histoire et société. Mélanges offerts à Georges Duby, Aix-en-Provence, Publications de l'Université de Provence, t. IV, 1992, pp. 77-85 (ici encore, l'indication de la publication originale a été omise, mais se retrouve grâce à la bibliographie finale). Les deux contributions inédites sont Silvère MENEGALDO, «Entre mer et forêt. Symbolique spatiale et géographique dans La Queste del Saint Graal», pp. 267-280 et Ollivier ERRECADE, «Piété rituelle et piété personnelle dans La Queste del Saint Graal», pp. 281-296. La traduction et la reproduction ont été exécutées avec une fidélité extrême au point que des références bibliographiques et des renvois internes que comportait la publication originale ont été gardés tels quels et mènent done maintenant dans le vide. Toutefois, le choix des articles, assez œcuménique, est sans aucun doute représentatif de ce qui s'est écrit ces derniers temps au sujet de la Queste. On regrettera simplement, mais il faudrait pour cela repenser l'exercice de l'agrégation, qu'on n'ait pas inclus des articles moins 
modernes. Les travaux les plus anciens sont ceux de Jean-Charles Payen qui datent des années 1960 et concernent des aspects «historiques» plus que «littéraires». Tous les autres sont nettement postérieurs et reflètent, malgré leur diversité, la doxa universitaire post 1970. L'inclusion des quelques études pionnières aurait permis de montrer aux étudiants que les paramètres en fonction desquels sont lus nos textes du Moyen Âge évoluent. Cela aurait peut- être pu les inciter à réfléchir sur les leurs, mais il est vrai que ce n'est pas ce qu'on demande à l'épreuve de l'agrégation. 